\title{
Burying as a species-specific defensive reaction: Differential performance of rats, mice, guinea pigs, and hamsters
}

\author{
JAMES CLEARY, SCOTT WALLACE, and ALAN POLING \\ Western Michigan University, Kalamazoo, Michigan 49008
}

\begin{abstract}
Previous investigations have shown that rats and some strains of mice, but not hamsters, selectively bury prods through which electric shocks are delivered. Rats also bury noxious foods, although this behavior has never been examined in other rodents. In the present study, albino rats and CF-1 mice gave some evidence of burying spouts filled with Tabasco sauce, an intrinsically aversive liquid, or sweetened condensed milk to which a taste aversion was conditioned. Such spouts were never buried by Syrian golden hamsters or by English short-haired guinea pigs. These results suggest that burying sources of aversive stimulation is a speciesspecific reaction not evident in all rodents.
\end{abstract}

Several recent studies have shown that rats will bury sources of aversive stimulation. Pinel and Treit (1978) reported that rats used bedding material to bury a shock prod but did not bury a similar prod not paired with electric shock. In addition to shock prods, other sources of aversive stimulation that have evoked burying include mousetraps, flashbulbs, and tubes that produce puffs of air (Terlecki, Pinel, \& Treit, 1979). Burying has also been shown to occur in response to neutral stimuli, such as marbles, and to appetitive stimuli, such as food pellets (Poling, Cleary, \& Monaghan, 1981). Whether burying of neutral and appetitive stimuli is fundamentally different from burying in response to aversive stimulation remains unclear.

Pinel and associates have proposed that burying in response to aversive stimulation is a defensive reaction, innate in rats (Pinel \& Treit, 1978; Wilkie, MacLennan, \& Pinel, 1979). Earlier, Bolles (1970) described fleeing, fighting, and freezing as species-specific defensive reactions in rats. According to him, rats that exhibited these responses to an aversive stimulus (e.g., a predator) were more likely to have survived and reproduced than were rats that failed to do so, and thus species-specific defensive reactions developed through natural selection.

The most convincing evidence that burying of aversive stimuli might have survival value in the natural environment of rats comes from studies employing noxious food. Wilkie et al. (1979) showed that rats would bury spouts filled with either an intrinsically bad-tasting liquid (Tabasco sauce) or a palatable liquid to which a taste aversion had been conditioned. Poling et al. (1981)

Preparation of this paper was supported by a Faculty Research Fellowship awarded to Alan Poling by Western Michigan University. We thank Mitchell Picker for his helpful comments on an earlier version. reported similar findings and also demonstrated that rats would bury quinine-coated food pellets.

One method of assessing the generality of the burying response is by comparing its strength in related species. Burying by rodent species other than rats has previously been investigated using the shock-prod procedure (Treit, Terlecki, \& Pinel, 1980; Whillans \& Shettleworth, 1981). While several strains of rats and two of three strains of mice buried the shock prod, neither hamsters nor gerbils showed any tendency to bury the offending prod. To further investigate the species-specific nature of the burying response, the present study employed the noxious-food procedure with four species of rodents. This procedure may more closely resemble situations that could be encountered in rodents' natural environments than does the shock-prod procedure.

\section{METHOD}

Subjects and Apparatus

Four adult male Sprague-Dawley albino rats $(220-300 \mathrm{~g})$ CR-1 albino mice (25-30 g), Syrian golden hamsters (75-100 g), and English short-haired guinea pigs $(500-550 \mathrm{~g})$ served as subjects. All animals were housed under constant illumination. Unless otherwise stated, appropriate Purina Laboratory Chow and tap water were available ad lib.

All subjects were individually housed in identical chambers $25 \mathrm{~cm}$ wide, $35 \mathrm{~cm}$ long, and $19 \mathrm{~cm}$ high. Except for a clear plastic front wall and ceiling, the entire chamber was constructed of aluminum. Chambers were equipped with a feeder tray or wire-mesh feeder hung from the rear wall $7 \mathrm{~cm}$ above the floor. A hole in each side wall, through which a drinking spout could be inserted, was located $6 \mathrm{~cm}$ from the front wall and $7 \mathrm{~cm}$ above the floor. Wood chips evenly distributed over the entire floor to a height of $4 \mathrm{~cm}$ served as bedding material.

Procedure

A 7-day acclimation period was arranged prior to the beginning of testing. During this period, tap water was continuously available from both spouts. After acclimation, water access was 
restricted to $1 \mathrm{~h} /$ day for 5 consecutive days. Bedding was always leveled prior to the insertion of the two drinking spouts.

After 5 days of restricted access to water, all subjects were tested by exposing them to undiluted Tabasco pepper sauce (McIlhenny Company, New Iberia, Louisanna). Testing consisted of inserting one spout, filled with Tabasco sauce, into the chamber at the beginning of the usual drinking period. Each subject was observed to sniff and/or lick this spout. Thirty minutes after the Tabasco-filled spout was inserted, the second spout, filled with tap water, was inserted and the bedding leveled at a height of $4 \mathrm{~cm}$. The height of the bedding at each spout was measured once each hour for the first $8 \mathrm{~h}$, after $24 \mathrm{~h}$, and again after $48 \mathrm{~h}$. Following the test with Tabasco sauce, 3 days of limited access to water intervened before subjects were tested under a taste aversion paradigm.

In taste aversion conditioning, each subject was exposed to a 1:1 mixture of water and sweetened condensed milk (Borden, Inc., Columbus, Ohio) for $30 \mathrm{~min}$ at the onset of the usual drinking period. Each subject was observed to sniff and/or lick the spout containing milk. After $30 \mathrm{~min}$ of exposure to the milk, subjects were removed from the chamber and injected intraperitoneally with $127 \mathrm{mg} / \mathrm{kg}$ lithium chloride (Sigma Chemical Company, St. Louis, Missouri) dissolved in isotonic saline solution. After injection, subjects were immediately returned to the chamber, with the bedding leveled to a depth of $4 \mathrm{~cm}$ and the second spout, filled with tap water, inserted. Measurements of bedding height at the two spouts were taken every hour for $8 \mathrm{~h}$, after $24 \mathrm{~h}$, and again after $48 \mathrm{~h}$.

\section{RESULTS AND DISCUSSION}

None of the species and strains tested in the present study showed unambiguous evidence of burying. Rats of the Sprague-Dawley strain failed to show the robust burying that previously had been demonstrated in Long-Evans hooded rats tested under identical procedures in this laboratory (Poling et al., 1981). Mice showed some evidence of burying the intrinsically aversive liquid (Tabasco sauce), but results with the conditioned aversive stimulus (sweetened condensed milk) were inconclusive. Certainly, this stimulus failed to evoke consistent burying by mice. Neither hamsters nor guinea pigs showed any tendency to bury either test stimulus.

Figure 1 shows time-course data on burying by rats
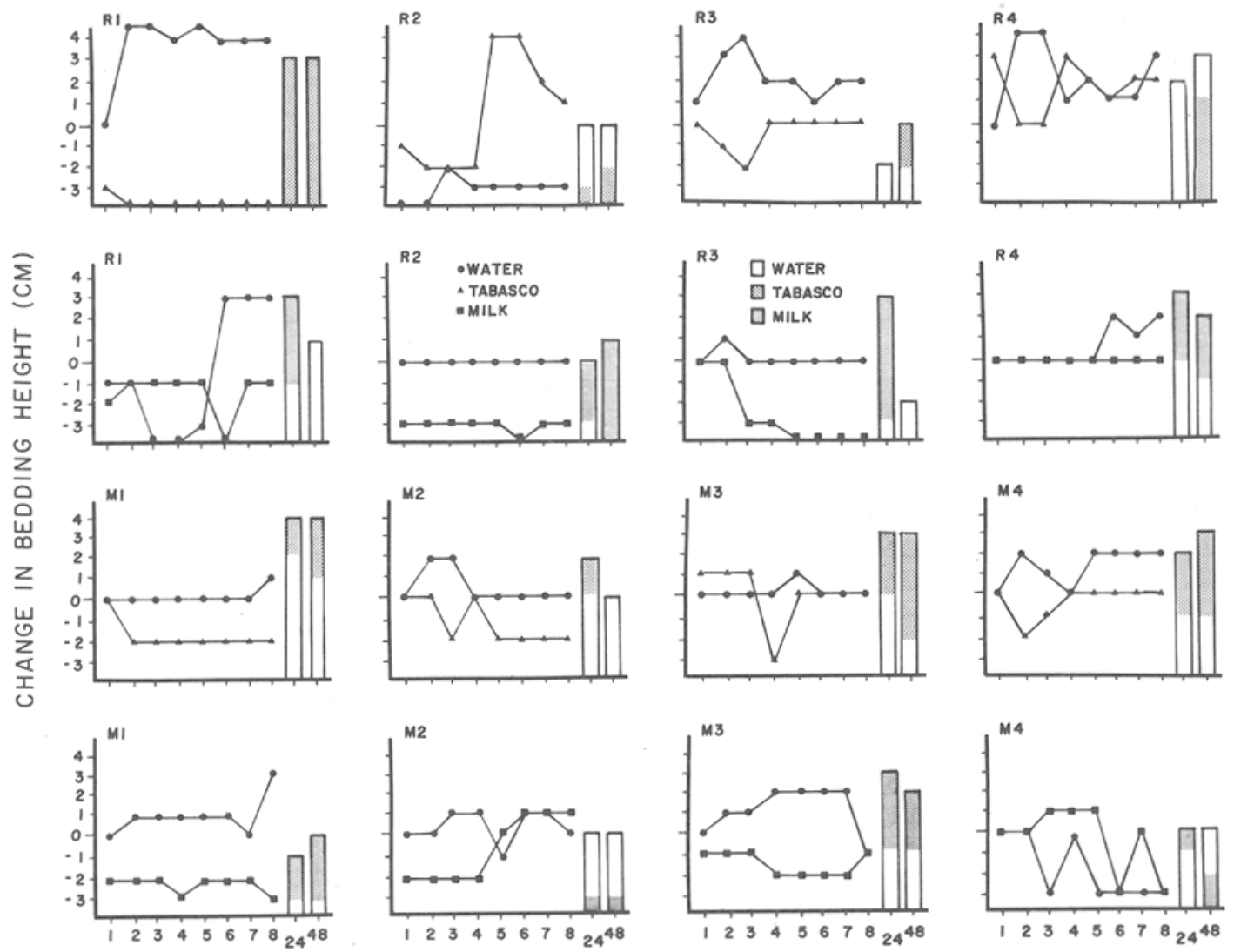

HOURS AFTER EXPOSURE

Figure 1. Change in bedding height at the two spouts at various times after their introduction. The performance of rats (R1, R2, R3, R4) when exposed to an intrinsically aversive liquid (Tabasco sauce) and a palatable liquid (milk) to which a taste aversion was conditioned is depicted in the first and second set of frames, respectively. Performance of mice (M1, M2, M3, M4) under these conditions is shown in the third and fourth set of frames. 
and mice for Tabasco sauce, sweetened condensed milk, and water. Three of four rats buried the Tabasco-filled spout at some point during the 48 -h observational period. However, only two of four rats buried this spout and left the water spout uncovered. In addition, only one rat allowed bedding to remain over the Tabascofilled spout for more than $24 \mathrm{~h}$.

Sweetened condensed milk, to which a taste aversion had been conditioned, also failed to evoke strong burying. Three of four rats shoved bedding material up to the level of the milk spout at some time during the $48 \mathrm{~h}$ of observation, but no rat actually covered the spout. Previous research in this laboratory has shown similar results with hooded rats (Poling et al., 1981), although this strain actually covered the spout on occasion. Hooded rats, like the albinos in the present study, buried only after several hours of exposure to the conditioned aversive stimulus. This delay in burying may be due to the prolonged discomfort induced by the lithium chloride used in the taste aversion conditioning.

Mice showed some tendency to bury the spout filled with Tabasco sauce, although only one mouse completely covered the spout with bedding. In contrast to rats, which usually buried the Tabasco-filled spout within $2 \mathrm{~h}$, most burying by mice appeared after $24 \mathrm{~h}$. Two mice shoved bedding toward the spout containing the conditioned aversive stimulus (sweetened condensed milk) at some point during the study, but none of the mice totally covered the milk spout with bedding.

Figure 2 presents burying data for hamsters and guinea pigs. Hamsters routinely moved a substantial amount of bedding material in their chambers, making nests and burying food, whereas guinea pigs rarely rearranged bedding. Neither of these species buried test spouts at any time, and thus bedding levels after $24 \mathrm{~h}$ are the only data presented in Figure 2.

It is apparent from the preceding data, and those reported in earlier studies (Treit et al., 1980; Whillans \& Shettleworth, 1981), that there is considerable variability in the strength of the burying response across species. Indeed, hamsters and guinea pigs appear not to bury noxious stimuli. In species that do bury aversive stimuli, most notably rats, the response is quickly learned, robust, and widely employed in response to a variety of noxious stimuli (Poling et al., 1981; Wilkie et al., 1979). This suggests that rats' burying of aversive stimuli is perhaps accurately construed as a speciesspecific defensive reaction.

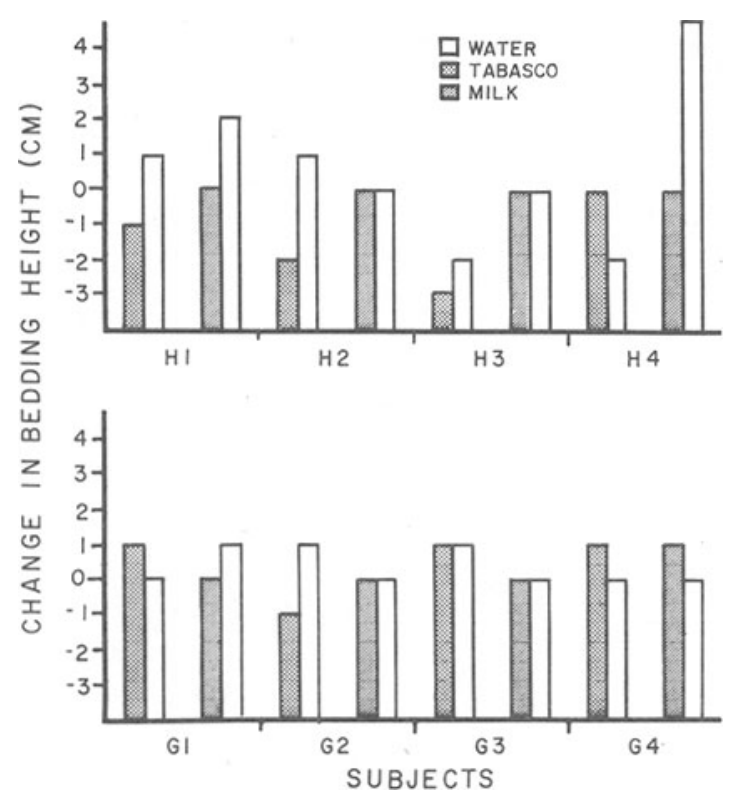

Figure 2. Change in bedding height at the two spouts $24 \mathrm{~h}$ after their introduction. The performance of hamsters $(\mathrm{H1}, \mathrm{H} 2$, H3, H4) when exposed to an intrinsically aversive liquid (Tabasco sauce) and a palatable liquid (milk) to which a taste aversion was conditioned is depicted in the first frame. Performance of guinea pigs (G1, G2, G3, G4) under these conditions is shown in the second frame.

\section{REFERENCES}

Bolles, R. C. Species-specific defensive reactions and avoidance learning. Psychological Review, 1970, 77, 32-48.

Pinel, J. P. J., \& Treit, D. Burying as a defensive response in rats. Journal of Comparative and Physiological Psychology, 1978, 92, 708-712.

Poling, A., Cleary, J., \& Monaghan, M. Burying by rats in response to aversive and nonaversive stimuli. Journal of the Experimental Analysis of Behavior, 1981, 35, 31-44.

Terlecki, L. J., Pinel, J. P. J., \& Treit, D. Conditioned and unconditioned burying in the rat. Learning and Motivation, 1979, 10, 337-350.

Treit, D., Terlecki, L. J., \& Pinel, J. P. J. Conditioned defensive burying in rodents: Organismic variables. Bulletin of the Psychonomic Society, 1980, 16, 451-454.

Whillans, K. V., \& Shettleworth, S. J. Defensive burying in rats and hamsters. Animal Learning \& Behavior, 1981, 9, 357-362.

Wilkie, D. M., Maclennan, A. J., \& Pinel, J. P. J. Rat defensive burying: Burying noxious food. Journal of the Experimental Analysis of Behavior, 1979, 31, 299-306.

(Received for publication May 7, 1982.) 